\title{
Reverse of Age-Dependent Memory Impairment and Mitochondrial DNA Damage in Microglia by an Overexpression of Human Mitochondrial Transcription Factor A in Mice
}

\author{
Yoshinori Hayashi, ${ }^{1 \star}$ Masayoshi Yoshida,,${ }^{2,4 \star}$ Mayumi Yamato, ${ }^{3 \star}$ Tomomi Ide, ${ }^{2}$ Zhou Wu, ${ }^{1}$ Mayumi Ochi-Shindou, ${ }^{1}$ \\ Tomotake Kanki, ${ }^{4}$ Dongchon Kang, ${ }^{4}$ Kenji Sunagawa, ${ }^{2}$ Hiroyuki Tsutsui, ${ }^{5}$ and Hiroshi Nakanishi ${ }^{1}$ \\ ${ }^{1}$ Laboratory of Oral Aging Science, Faculty of Dental Sciences, ${ }^{2}$ Department of Cardiovascular Medicine, Graduate School of Medical Sciences, ${ }^{3}$ Department \\ of REDOX Medicinal Science, Graduate School of Pharmaceutical Sciences, ${ }^{4}$ Department of Clinical Chemistry and Laboratory Medicine, Kyushu \\ University, Fukuoka 812-8582, Japan, and 5 Department of Cardiovascular Medicine, Hokkaido University Graduate School of Medicine, Sapporo 060-8638, \\ Japan
}

\begin{abstract}
Mitochondrial DNA (mtDNA) is highly susceptible to injury induced by reactive oxygen species (ROS). During aging, mutations of mtDNA accumulate to induce dysfunction of the respiratory chain, resulting in the enhanced ROS production. Therefore, age-dependent memory impairment may result from oxidative stress derived from the respiratory chain. Mitochondrial transcription factor A (TFAM) is now known to have roles not only in the replication of mtDNA but also its maintenance. We herein report that an overexpression of TFAM in HeLa cells significantly inhibited rotenone-induced mitochondrial ROS generation and the subsequent NF- $\kappa \mathrm{B}$ (nuclear factor$\kappa \mathrm{B})$ nuclear translocation. Furthermore, TFAM transgenic (TG) mice exhibited a prominent amelioration of an age-dependent accumulation of lipid peroxidation products and a decline in the activities of complexes I and IV in the brain. In the aged TG mice, deficits of the motor learning memory, the working memory, and the hippocampal long-term potentiation (LTP) were also significantly improved. The expression level of interleukin-1 $\beta$ (IL-1 $\beta$ ) and mtDNA damages, which were predominantly found in microglia, significantly decreased in the aged TG mice. The IL-1 $\beta$ amount markedly increased in the brain of the TG mice after treatment with lipopolysaccharide (LPS), whereas its mean amount was significantly lower than that of the LPS-treated aged wild-type mice. At the same time, an increased mtDNA damage in microglia and an impaired hippocampal LTP were also observed in the LPS-treated aged TG mice. Together, an overexpression of TFAM is therefore considered to ameliorate age-dependent impairment of the brain functions through the prevention of oxidative stress and mitochondrial dysfunctions in microglia.
\end{abstract}

Key words: mitochondria DNA; transcription factor A; oxidative stress; aging; memory impairment; microglia

\section{Introduction}

It is widely believed that oxidative stress and inflammation are major causative factors for a progressive decline in motor and

Received March 3, 2008; revised July 7, 2008; accepted July 15, 2008.

This work was supported by Grants-in-Aid for Scientific Research and Grant-in-Aid for Scientific Research on Priority Area from the Ministry for Education, Science, and Culture, Japan; a Labor Science Research Grant for Comprehensive Research in Aging and Health Labor and Welfare of Japan; and the Uehara Research Foundation. We thank Prof. V. Hugh Perry (CNS Inflammation Group, School of Biological Sciences, University of Southampton, Southampton, UK) for his critical reading of this manuscript. We also thank Keiko Kurakazu for technical assistance and Drs. Atsushi Fukuoh and Kippei Ohgaki for technical advice.

*Y.H., M. Yoshida, and M. Yamato contributed equally to this work.

Correspondence should be addressed to either of the following: Dr. Tomomi Ide, Department of Cardiovascular Medicine, Kyushu University Graduate School of Medicine, 3-1-1, Maidashi, Higashi-ku, Fukuoka 812-8582, Japan, E-mail: tomomi_i@cardiol.med.kyushu-u.ac.jp; or Dr. Hiroshi Nakanishi, Laboratory of Oral Aging Science, Faculty of Dental Sciences, Kyushu University, 3-1-1, Maidashi, Higashi-ku, Fukuoka 812-8582, Japan, E-mail: nakan@dent.kyushu-u.ac.jp.

M. Ochi-Shindou's present address: Neurobiology Research Unit, Okinawa Institute of Science and Technology, Okinawa 904-2234, Japan.

DOI:10.1523/JNEUROSCI.1957-08.2008

Copyright @ 2008 Society for Neuroscience $\quad$ 0270-6474/08/288624-11\$15.00/0 memory functions during aging in humans and animals (Forster et al., 1996; Navarro et al., 2002). Behavioral dysfunctions associated with aging are also postulated to be associated with a decreased activity of mitochondrial electron transfer complexes with aging (Navarro et al., 2004, 2005). Furthermore, increased intracellular reactive oxygen species (ROS) activate microglia, which are representative resident mononuclear phagocyte populations in the brain, to induce an increased production of inflammatory mediators (Pawate et al., 2004; Qin et al., 2005). ROS generated in close proximity and in large concentrations by the mitochondrial respiratory chain cause oxidation of unsaturated fatty acid, proteins, and DNA. Mitochondrial DNA (mtDNA) is highly susceptible to damage produced by ROS because of its close proximity to ROS generation through the respiratory chain and its paucity of protective histones. Furthermore, there is little capacity for DNA repair in the mitochondria. During aging, a large number of mtDNA mutations accumulate in various tissues including the brain, thus leading to dysfunction of the respiratory 
chain. Finally, deficits in the respiratory chain result in the enhanced ROS production, culminating in age-dependent memory impairments (Corral-Debrinski et al., 1992; Lin et al., 2002). Therefore, the vulnerability of mtDNA to ROS is a major determinant factor for deficits in the brain functions in aging.

Mitochondrial transcription factor A (TFAM) is a nucleusencoded protein that binds upstream of the light-strand and heat-strand promoters of mtDNA and promotes the transcription of mtDNA (Parisi and Clayton, 1991). Moreover, there is increasing evidence that TFAM plays an important role in maintaining mtDNA and regulating its copy number. The amount of mtDNA is closely correlated with the amount of TFAM but not with the transcription level, and the majority of TFAM molecules are involved in architecturally maintaining the higher structure of mtDNA (Kanki et al., 2004b). More recently, transgenic mice that overexpressed human TFAM under control of the $\beta$-actin promoter were generated and showed an increased copy number of mtDNA in the myocardium and the protection of the heart from mitochondrial dysfunction (Ikeuchi et al., 2005). The improvement in mitochondrial respiratory function may thus lead to an amelioration of the chronic process of remodeling by decreasing the mitochondrial ROS generation. The brain has a higher demand for oxygen; therefore, it is possible that increased oxidative stress and consequent mtDNA mutations may lead to the accumulation of lipid peroxidation products. Furthermore, it is reasonable to speculate that such TFAM overexpression may also inhibit the mitochondrial ROS generation through a reduction of the mtDNA mutations, which may retard the motor and memory functions.

To address this issue, the effects of TFAM overexpression on age-dependent deficits in brain functions were examined using human TFAM transgenic (TG) mice. The present study showed a significant improvement in the age-dependent memory impairments in TG mice because of a marked reduction in both oxidative stress and inflammation in the brain.

\section{Materials and Methods}

All experimental procedures of this study were approved by the Animal Care and Use Committee of Kyushu University.

Overexpression of TFAM in HeLa cells using the tetracycline-regulation system. Tetracycline-regulated TFAM-overexpressing cell lines were produced as previously reported (Parisi and Clayton, 1991). The cells were grown in DMEM containing 10\% fetal bovine serum, $400 \mathrm{mg} / \mathrm{ml}$ Geneticin (G418), and $200 \mathrm{mg} / \mathrm{ml}$ hygromycin $\mathrm{B}$, with or without $1 \mathrm{mg} / \mathrm{ml}$ doxycycline (DC) and maintained at $37^{\circ} \mathrm{C}$ in humidified air with $5 \%$ $\mathrm{CO}_{2}$. The cells were then seeded in 24-well dishes and the culture medium was replaced after $24 \mathrm{~h}$ with serum-free DMEM containing 400 $\mathrm{mg} / \mathrm{ml} \mathrm{G} 418$ and $200 \mathrm{mg} / \mathrm{ml}$ hygromycin B, with or without $1 \mathrm{mg} / \mathrm{ml} \mathrm{DC}$. After $24 \mathrm{~h}$, the cells were treated for $6 \mathrm{~h}$ with $0.001 \%$ of $1 \mathrm{~mol} / \mathrm{L}$ rotenone dissolved in ethanol. The protein levels of human TFAM in the soluble fractions of HeLa cells in the presence and absence of DC were analyzed by immunoblotting.

Rotenone-induced ROS measurement. Intracellular ROS was measured by a ROS-sensitive fluorescent probe, 2,7-diamino-10-ethyl-9-phenyl9,10-dihydrophenanthridine (DHE), in tetracycline-regulated HeLa cells. The cells were plated in 96-well culture dishes and cultured for $24 \mathrm{~h}$ at $37^{\circ} \mathrm{C}$ in humidified air with $5 \% \mathrm{CO}_{2}$, followed by incubation in serumfree medium for another $24 \mathrm{~h}$. Next, the cells were treated with $1 \mu \mathrm{mol} / \mathrm{L}$ rotenone for $5.5 \mathrm{~h}$ and then with $2 \mu \mathrm{mol} / \mathrm{L}$ DHE for $30 \mathrm{~min}$. The fluorescent intensity was determined immediately at excitation wavelength of $485 \mathrm{~nm}$ and emission wavelength of $530 \mathrm{~nm}$ on a fluorescent plate reader. The cellular images for DHE oxidation were observed using confocal laser-scanning microscope (CLSM) (LSM510MET; Carl Zeiss).

CLSM images for nuclear factor- $\kappa B$ nuclear translocation. Tetracyclineregulated TFAM-overexpressing HeLa cells were seeded in 24-well dish
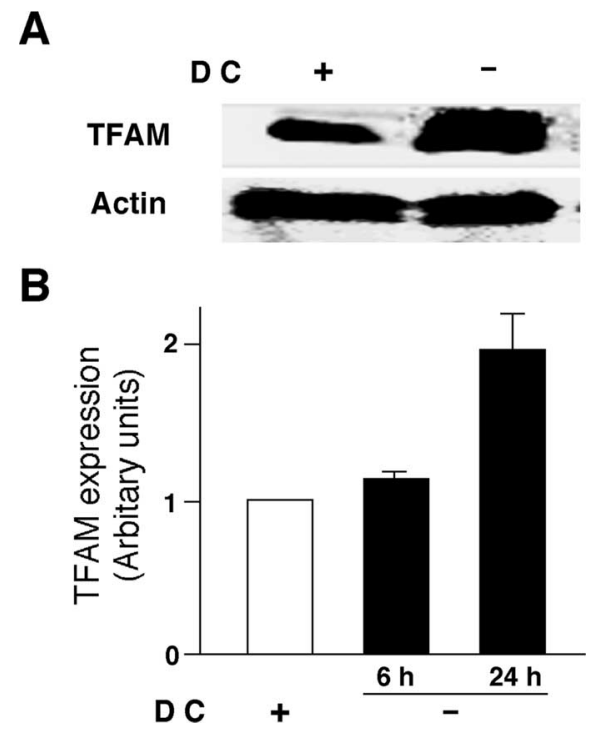

Figure 1. Protein levels of human TFAM overexpressed by the tetracycline-off system in HeLa cells. $A$, Immunoblot analysis of human TFAM expressed in HeLa cells cultured with and without DC for $24 \mathrm{~h}$. $\boldsymbol{B}$, The mean protein level of human TFAM in HeLa cells cultured with and without $D C$ for 6 and $24 \mathrm{~h}$. The mean relative immunoreactivity of each protein band was determined using the level of actin as an internal control. Each column and bar represent the mean and SEM of three experiments, respectively.

at a density of $10^{3}$ cells $/ \mathrm{mm}^{2}$. The culture medium was replaced after $24 \mathrm{~h}$ with serum-free DMEM medium containing $400 \mathrm{mg} / \mathrm{ml} \mathrm{G} 418$ and $200 \mathrm{mg} / \mathrm{ml}$ hygromycin B, with or without $1 \mathrm{mg} / \mathrm{ml} \mathrm{DC}$. After $24 \mathrm{~h}$, the cells were treated for $6 \mathrm{~h}$ with $0.001 \%$ (final concentration in medium) of $1 \mathrm{~mol} / \mathrm{L}$ rotenone dissolved in ethanol. After treatment with rotenone or vehicle, the cells were fixed with $4 \%$ paraformaldehyde and then incubated with mouse anti-p65 monoclonal antibody (Santa Cruz Biotechnology; AH Diagnostics) in bovine serum albumin (BSA)/PBS overnight at $4^{\circ} \mathrm{C}$, washed three times with PBS, and then incubated with a secondary Alexa 488 goat anti-mouse IgG antibody in BSA/PBS for $1 \mathrm{~h}$ at room temperature. After three washes, the nuclei of cells were counterstained with propidium iodide (Sigma-Aldrich). The cells showing bright staining for $\mathrm{p} 65$ in the nucleus were scored, and the results were presented as a percentage of the number of cells with nuclear factor- $\kappa \mathrm{B}(\mathrm{NF}-\kappa \mathrm{B})$ nuclear translocation to the total number of cells examined.

Animals. The methods for generating TG mice that overexpressed human TFAM has been described previously (Ikeuchi et al., 2005). The animals were housed under $12 \mathrm{~h}$ light/dark cycle (lights on at 8:00 A.M.) with access to food and water ad libitum. All mice were handled daily for $5 \mathrm{~d}$ before the start of the experiment to minimize stress reactions to manipulation.

Immunoblotting. Antibodies against human TFAM and mouse Tfam were produced by immunizing rabbits with recombinant glutathione $S$-transferase-tagged human TFAM and mouse Tfam. The protein levels of human TFAM and mouse endogenous TFAM were analyzed in the soluble fractions of brain tissue homogenates as previously described (Lin et al., 2002).

Thiobarbituric acid reactive substances. Twenty male C57BL/6 mice [wild type (WT) and TG] of the following age groups: young (2 months of age; WT, $n=5$; TG, $n=5$ ) and aged (24 months of age; WT, $n=5$; TG, $n=5$ ) were used for the measurement of thiobarbituric acid reactive substances (TBARS). The homogenates of whole brains were mixed with $0.4 \%$ SDS, $7.5 \%$ acetic acid adjusted to $\mathrm{pH} 3.5$ with $\mathrm{NaOH}$, and $0.3 \%$ thiobarbituric acid. The mixture was kept at $5^{\circ} \mathrm{C}$ for $60 \mathrm{~min}$ and then heated at $100^{\circ} \mathrm{C}$ for $60 \mathrm{~min}$. After cooling, the mixture was extracted with distilled water and $n$-butanol:pyridine $(15: 1, \mathrm{v} / \mathrm{v})$ and centrifuged at $16,000 \times g$ for $10 \mathrm{~min}$. The fluorescence of the supernatant was measured at excitation and emission wavelengths of 510 and $550 \mathrm{~nm}$, respectively, using GENios Pro (Tecan). The standard was prepared using TEP (1,1,3,3-tetraethoxypropane). 

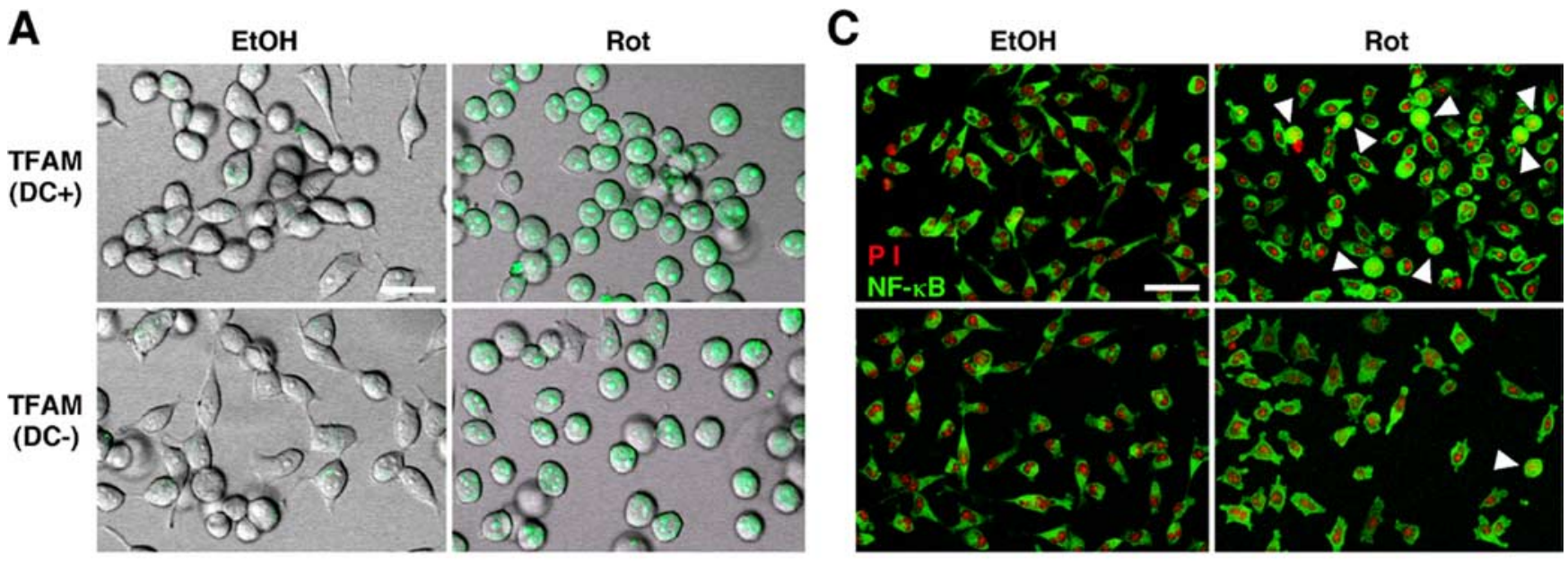

B
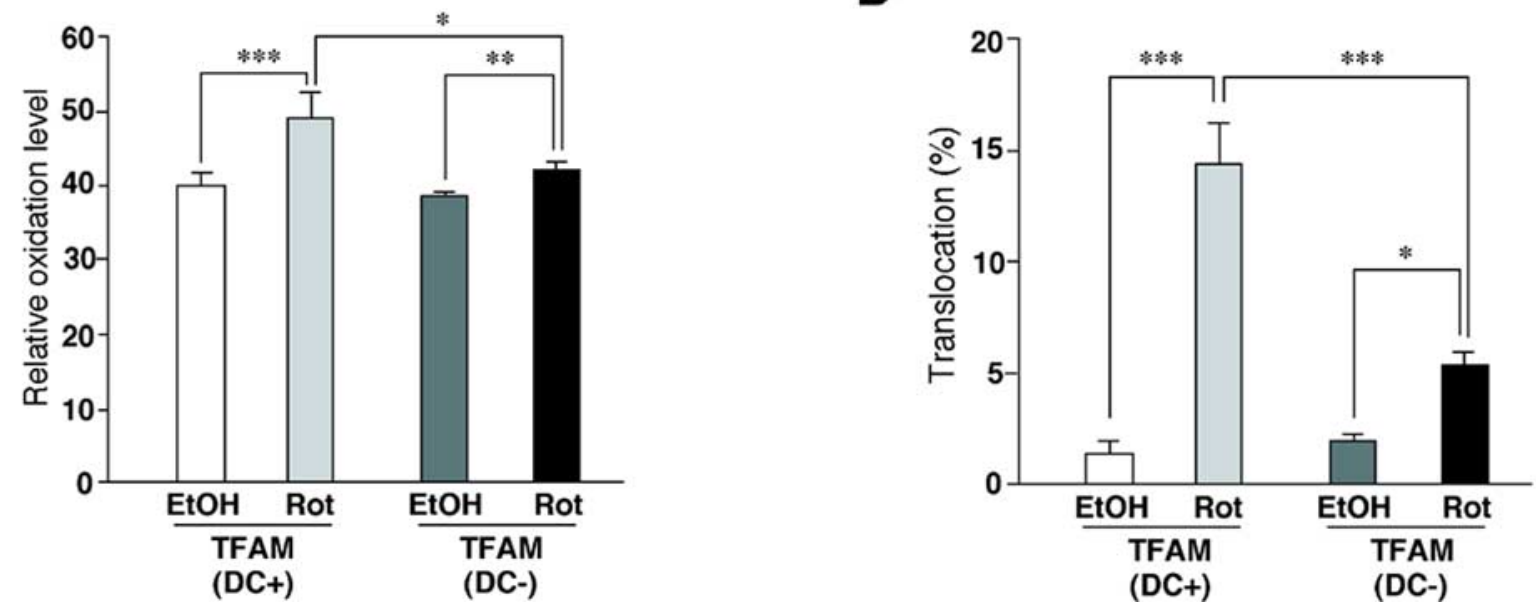

Figure 2. Effects of an overexpression of TFAM by the tetracycline-off system on rotenone-induced intracellular ROS generation and NF- $\kappa$ B nuclear translocation in HeLa cells. A, CLMS images of rotenone-induced intracellular ROS generation measured using a ROS-sensitive dye (green), DHE, in HeLa cells cultured with or without DC. Scale bar, $20 \mu \mathrm{m}$. B, The mean DHE oxidation levels in HeLa cells cultured with or without $D C$ after treatment with $\mathrm{EtOH}$ or rotenone. Each column and bar represent the mean \pm SEM of six experiments. The asterisks indicate a significant difference between two groups $\left({ }^{*} p<0.05 ;{ }^{* *} p<0.01 ; * * * 00.001\right)$. C, NF- $\kappa$ B (green) and propidium iodide (PI)-stained nuclei (red) in HeLa cells cultured with or without DC after the treatment with EtOH or rotenone. The arrowheads show HeLa cells with the nuclear translocated NF- $\kappa$ B. Scale bar, $50 \mu \mathrm{m}$. D. The mean percentage of the NF- $\kappa$ B nuclear translocation in HeLa cells cultured with or without $\mathrm{DC}$ after the treatment with EtOH or rotenone. Each column and bar represent the mean \pm SEM of nine experiments. The asterisks indicate significant differences between two groups $\left({ }^{*} p<\right.$ $\left.0.05 ;{ }^{* * *} p<0.001\right)$. Rot, Rotenone.

Mitochondrial enzyme activities. Twenty male C57BL/6 mice (WT and TG) of the following age groups: young ( 2 months of age; WT, $n=5$; TG, $n=5$ ) and aged (24 months of age; WT, $n=5$; TG, $n=5$ ) were used to measure the mitochondrial enzyme activities. The specific activity of mitochondrial complex enzymes, including complexes I, II, III, and IV, was measured in mitochondria isolated from whole brains of each group as described previously (Ide et al., 1999). The specific activity of rotenone-sensitive NADH-ubiquinone oxidoreductase (complex I) was measured by reduction of the ubiquinone analog decylubiquinone. For the activity of succinate ubiquinone oxidoreductase (complex II), the reduction of 2,6-dichlorophenolindophenol when coupled to complex II-catalyzed reduction of decylubiquinone was measured. For the specific activity of ubiquinol/cytochrome $c$ oxidoreductase (complex III), the reduction of cytochrome $c$ catalyzed by complex III in the presence of reduced decylubiquinone was monitored. The specific activity of cytochrome $c$ oxidase (complex IV) was measured by following the oxidation of reduced cytochrome $c$, which was prepared in the presence of dithionite. All enzymatic activities were expressed as nanomoles per minute per milligram of protein.

Immunohistochemistry. Twenty-four male C57BL/6 mice (WT and TG) of the following age groups: young (2-4 months of age; WT, $n=6$; TG, $n=6)$ and aged (20-24 months of age; WT, $n=6$; TG, $n=6)$ were used for the immunohistochemical analyses. WT and TG mice of both young and aged groups were anesthetized with sodium pentobarbital (40 $\mathrm{mg} / \mathrm{kg}$, i.p.) and killed by intracardiac perfusion with isotonic saline followed by PBS, $\mathrm{pH}$ 7.4. After perfusion, the brain was removed and further fixed by immersion in $4 \%$ paraformaldehyde overnight at $4^{\circ} \mathrm{C}$, and then immersed in $30 \%$ sucrose for $24 \mathrm{~h}$ at $4^{\circ} \mathrm{C}$. Floating coronal sections ( $10 \mu \mathrm{m}$ thick) of the hippocampus were prepared by a cryostat and stained with anti-human TFAM, anti-8-oxo-deoxyguanosine (8oxo-dG) (NOF Corporation), anti-4-hydroxy-2-nonenal (HNE) (Alpha Diagnostic), and anti-interleukin-1 $\beta$ (IL-1 $\beta$ ) (Santa Cruz Biotechnology) for $3 \mathrm{~d}$ at $4^{\circ} \mathrm{C}$. To detect any oxidative damage in the mitochondrial DNA rather than in the nuclear DNA, the sections were directly treated with anti-8-oxo-dG antibody without treatment of $\mathrm{HCl}$ as described previously (Kajitani et al., 2006). After washing with PBS, the sections were stained using the avidin-biotin-peroxidase complex method (Vector Laboratories). After washing with PBS, the sections were reacted with $0.015 \%$ 3',3-diaminobenzidine/0.4\% $\left(\mathrm{NH}_{4}\right)_{2} \mathrm{Ni}\left(\mathrm{SO}_{4}\right)_{2} / 0.09 \% \mathrm{H}_{2} \mathrm{O}_{2} / 0.1$ $\mathrm{mol} / \mathrm{L}$ Tris-buffered saline for 5-10 min. The sections were rinsed thoroughly with PBS, mounted, and coverslipped. As negative controls, the sections were incubated with nonimmune rabbit IgG or mouse IgG instead of the first antibody and processed in the same manner as described above.

For double fluorescent staining, the floating sections were stained with the following combinations of the first antibodies for $48 \mathrm{~h}$ at $4^{\circ} \mathrm{C}$ : anti- 
A

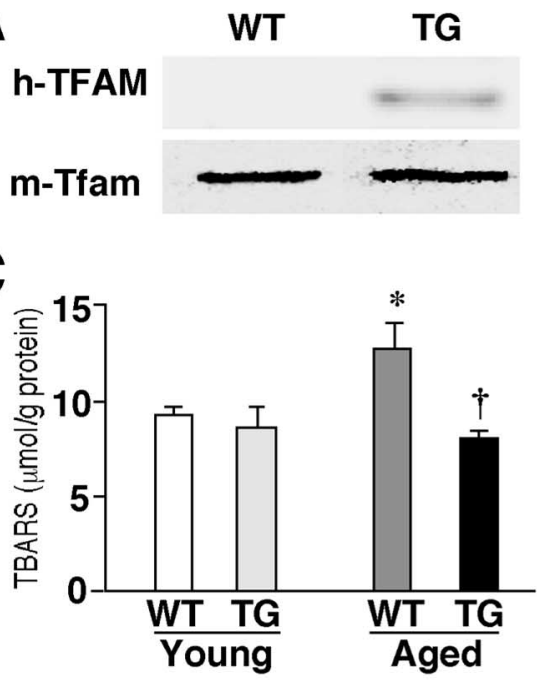

D
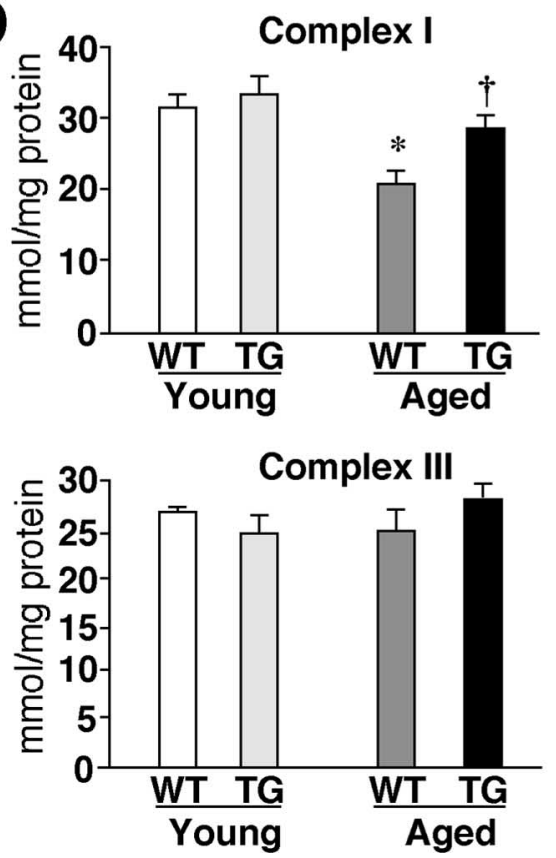

B

h-TFAM

\section{WT \\ (Aged)}

TG

(Aged)
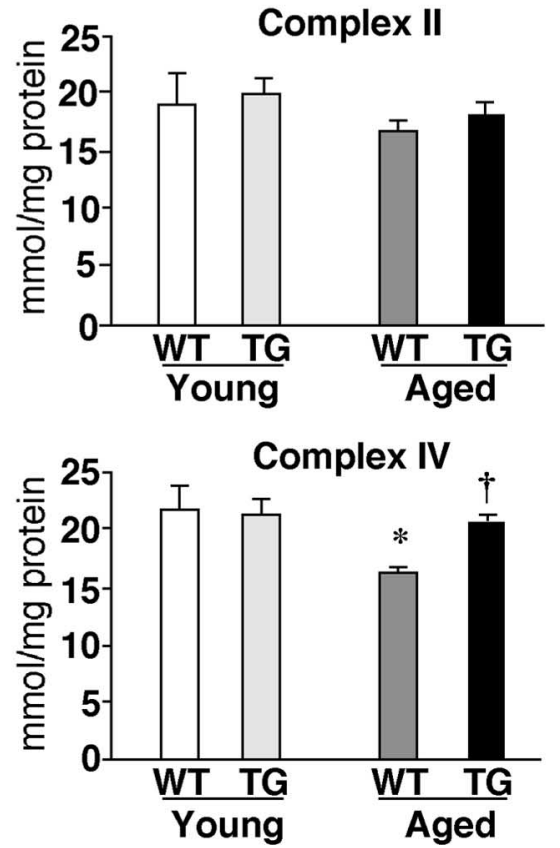

Figure 3. The effects of TFAM overexpression on age-dependent increased oxidative stress in the brain. $\boldsymbol{A}$, Expression of TFAM in the brain. Immunoblotting was performed using specific antibodies against human TFAM (h-TFAM) and mouse Tfam (m-Tfam) in soluble brain extracts prepared from the young WT and TG mice. $\boldsymbol{B}$, Immunohistochemical staining for H-TFAM in the CA1 hippocampal subfield of aged WT and TG mice. Scale bar, $50 \mu \mathrm{m}$. $\boldsymbol{C}$, The mean lipid peroxidation levels measured using a biochemical assay for TBARS in the brain tissues prepared from the WT and TG mice of both age groups. Each column and bar represent the mean \pm SEM of five experiments. An asterisk indicates a significant difference versus the young WT mice $\left(^{*} p<\right.$ 0.05). A dagger indicates a significant difference versus the aged WT mice $\left({ }^{\dagger} p<0.05\right)$. $\boldsymbol{D}$, The mean activity of mitochondrial respiratory enzymes, complexes I to IV, in brain tissues prepared from the WT and TG mice of both age groups. Each column and bar represent the mean \pm SEM of five experiments. The asterisks indicate significant differences versus the young WT mice $\left({ }^{*} p<\right.$ 0.05). The daggers indicate significant differences versus the aged WT mice ( ${ }^{\dagger} p<0.05$ ).

8-oxo-dG and anti-Ibal IgGs (Wako Pure Chemicals Industries); anti8-oxo-dG and anti-GFAP IgGs (Sigma-Aldrich); anti-8-oxo-dG and anti-MAP2 IgGs (Millipore Bioscience Research Reagents); anti-HNE IgG and F4/80 (Serotec); anti-HNE and anti-GFAP IgGs; anti-HNE and anti-NeuN IgGs (Millipore Bioscience Research Reagents); anti-IL-1 $\beta$ and anti-Iba1 IgGs; anti-IL- $1 \beta$ and anti-GFAP IgGs; anti-IL- $1 \beta$ and antiNeuN IgGs; 8-oxo-dG and anti-cytochrome $b$ (Cyt $b$ ) IgGs (Kanki et al., 2004b). After washing with PBS, the sections were incubated with a mixture of $0.5 \%$ Alexa 488 anti-mouse IgG and Cy3 anti-rabbit IgG, 0.5\% Alexa 488 anti-rabbit IgG and Cy3 anti-mouse IgG (GE Healthcare) for $2 \mathrm{~h}$ at room temperature. Some sections immunostained using anti-8-
oxo-dG and anti-HNE IgGs were stained with an RNA/DNA marker, YOYO-1 (Invitrogen). After several washes with PBS, the sections were mounted in the antifading medium Vectashield (Vector Laboratories) and examined with a CLSM (LSM510MET; Carl Zeiss). To quantitatively assess the immunofluorescence intensity of IL- $1 \beta$ in microglia, the immunofluorescence intensity of IL- $1 \beta$ within Ibal-positive cells was measured as the average pixel intensity. The immunofluorescence intensity of 8-oxo-dG within Cyt $b$-positive mitochondria was also measured as the average pixel intensity.

Behavioral tests. Twenty-four male C57BL/6 mice (WT and TG) of the following age groups: young ( 2 months of age; WT, $n=6$; TG, $n=6$ ) and aged (24 months of age; WT, $n=6$; TG, $n=6$ ) were used in the following behavioral tests.

For the cylinder test, the modified cylinder test was used to monitor locomotor activity in a novel environment (Tillerson et al., 2002). In short, each animal was placed in a glass cylinder (diameter, $10 \mathrm{~cm}$; height, $14 \mathrm{~cm}$ ) and was videotaped for $6 \mathrm{~min}$. The mice responded to the novel environment by standing on their hindlimbs and leaning on the walls of the cylinder with their forelimbs. The number of supporting paw placements performed independently with the left and the right paws were counted for the first $3 \mathrm{~min}$. The forelimb use score was described by expressing the total number of wall contacts performed with both forelimbs.

For the measurement of locomotor activities, mice were removed from their home cages and placed in a novel home cage (clean and without bedding), which provided a floor area of $28 \times$ $18 \mathrm{~cm}$, and then the locomotor activity of mice of each genotype and each different age group was scored for $3 \mathrm{~min}$. The novel home cage was divided into six identical rectangles and a trained observer determined the incidence of line crossing.

For the rotarod test, an automated single lane rotarod treadmill (Muromachi; $3 \mathrm{~cm}$ diameter drums with grooves to improve the grip) that could be set at either a fixed speed or an accelerating speed was used. For the fixed speed rotarod protocol, all mice were pretrained on the rotarod apparatus in order for them to reach a stable performance as described by Iancu et al. (2005). The training consisted of three sessions on 2 consecutive days, whereby each session included three separate test trials, each lasting $120 \mathrm{~s}$. The mice were trained at 5,10 , and 15 $\mathrm{rpm}$. On day 1 , mice were trained at $5 \mathrm{rpm}$. On day 2 , mice were trained once in the morning at $10 \mathrm{rpm}$ and once again in the afternoon at 15 $\mathrm{rpm}$. The final test (three sessions, each lasting $180 \mathrm{~s}$ ) was performed on the third day at $15 \mathrm{rpm}$. For each trial, the mouse was gently placed on the stopped rod, with its body axis perpendicular to the rotation axis and the head oriented to the same direction of rotation, so that the animal had to turn their position against the direction of rotation and progress forward to avoid a fall from the rod after the rod started to rotate. Between trials, the mice were given at least 10 min of rest to reduce stress and fatigue. The length of time that each animal was able to stay on the rod was recorded as the latency to fall, and it was registered automatically by a trip switch under the floor of the rotating drum.

For the radial maze test, an apparatus was created as described previ- 
ously (Morgan et al., 2000). The radial-arm water maze consisted of a circular pool measuring $1 \mathrm{~m}$ in diameter with six arms $19 \mathrm{~cm}$ wide that radiated out from an open central area, with a submerged escape platform located at the end of one of the arms. Spatial cues including a light were present on the wall of the testing room. The escape platform was placed in a different arm each day, forcing the mouse to use working memory to solve the task. On each trial, the mouse was started in one arm and allowed to swim for up to $1 \mathrm{~min}$ until finding the platform. The number of errors until the mouse reached the platform was recorded. After the fourth trial, the mouse was placed in a cage for $30 \mathrm{~min}$ and then returned to the maze and administered the fifth trial to assess memory retention. The error score was determined by the average score obtained from testing conducted during a $2 \mathrm{~d}$ period after training for $7 \mathrm{~d}$.

Systemic lipopolysaccharide injection. Thirtytwo male 24-month-old C57BL/6 mice were subjected to the systemic injection of either saline (WT, $n=8$; TG, $n=8$ ) or lipopolysaccharide (LPS) (WT, $n=3$; TG, $n=13$ ). The aged WT and TG mice were injected intraperitoneally with sterile saline or Escherichia coli LPS (0.33 mg/kg; serotype 055:B5; Sigma-Aldrich). In the first study, mice ( $n=3$ for each group) were killed at $4 \mathrm{~h}$ after saline or LPS injection and the soluble extracts of the whole brain were subjected to the immunoblot analyses using anti-IL- $1 \beta$ antibody to measure the total IL- $1 \beta$ level. The mean relative immunoreactivity of IL- $\beta$ was determined using expression of actin as an internal control. In a subsequent study, the immunofluorescence intensity of IL- $1 \beta /$ cell ( $n=3$ for each group), the immunofluorescence intensity of 8 -oxo-dG/mitochondria ( $n=2$ for each group), and the magnitude of the long-term potentiation (LTP) were evaluated in the hippocampus prepared from the aged TG mice that had been injected by LPS at $4 \mathrm{~h}$ earlier (TG, $n=5$ ).

Electrophysiology. Twenty-eight male C57BL/6 mice (WT and TG) of the following age groups: young (2-4 months of age; WT, $n=6$; TG, $n=5)$ and aged (19-22 months of age; WT, $n=10$; TG, $n=$ $7)$ were used in the electrophysiological study. The brain was removed rapidly and hippocampal slices were prepared by cutting $400-\mu$ m-thick sagittal sections using a microslicer (VT1000S; Leica) as described previously (Hayashi et al., 2006). Some mice were injected LPS $(0.33 \mathrm{mg} / \mathrm{kg}$; Sigma-Aldrich) intraperitoneally $4 \mathrm{~h}$ before recording. Field EPSPs evoked by stimulation of the Schaffer collateral pathway were recorded from the CA1 subfield. LTP was induced by tetanus stimulation consisting of a train of pulses of $1 \mathrm{~s}$ duration given at 25,50, and $100 \mathrm{~Hz}$. All data were captured using the PowerLab (Molecular Devices), and then they were digitized $(5-20 \mathrm{kHz})$ and stored on the hard disk of a personal computer for off-line analysis using the Scope software program.

Statistical analysis. Data are expressed as the mean \pm SEM. The statistical analyses were performed by an ANOVA.

\section{Results}

Inhibitory effect of TFAM overexpression on rotenoneinduced intracellular ROS generation and NF- $\kappa \mathrm{B}$ nuclear translocation in HeLa cells

TFAM overexpression may inhibit the ROS generation through reduction of mtDNA mutations, which subsequently retards the
B
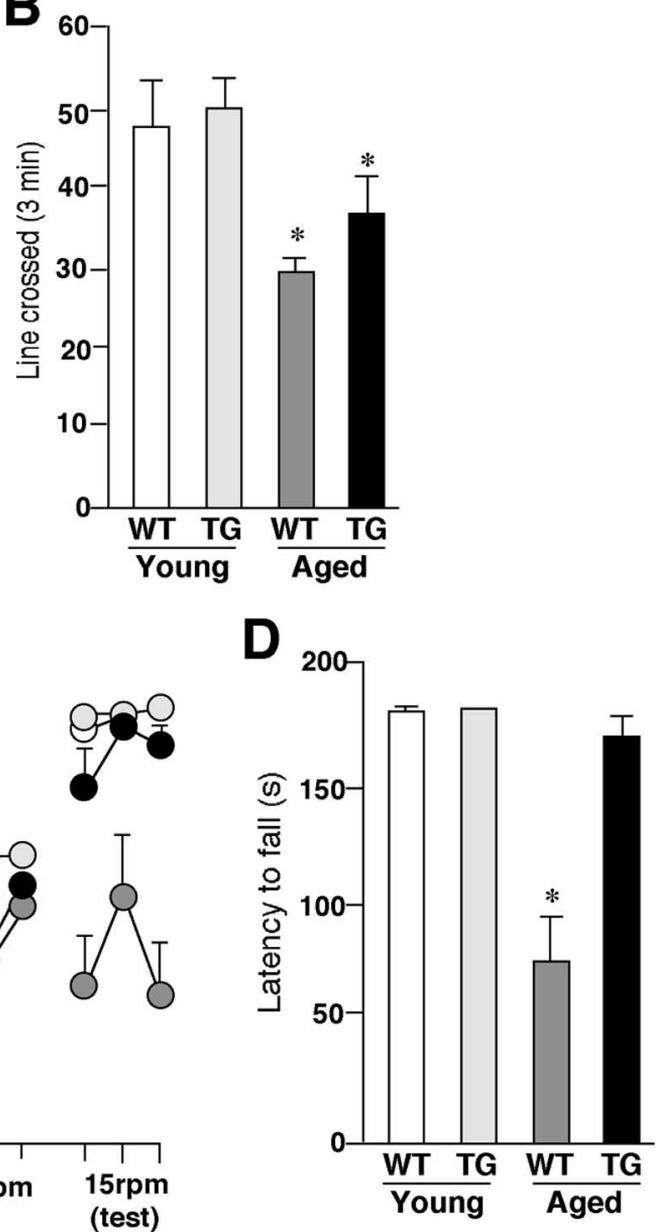

(test)
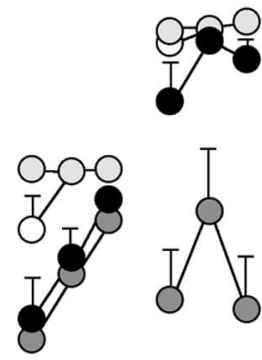

Figure 4. The amelioration of aged-dependent impairment of coordinated movements in the aged TG mice. $\boldsymbol{A}$, The mean total number of forepaw contacts. Each column and bar represent the mean \pm SEM of six animals. The asterisks indicate significant 政 test session (3 trials at $15 \mathrm{rpm}$ ). Each column and bar represents the mean $\pm \mathrm{SEM}$ of six animals. An asterisk indicates a significant difference versus the young group $\left({ }^{*} p<0.05\right)$.

motor and memory functions. To elucidate this deduction, the effects of TFAM on intracellular ROS generation were first examined in HeLa cells overexpressing human TFAM using the tetracycline-off system. The protein level of TFAM in the HeLa cells increased approximately twofold by removal of DC, a derivative of tetracycline, from the culture medium (Fig. 1). Rotenone, an inhibitor of mitochondrial complex I, was used to produce ROS, which originated from the mitochondria, because impaired electrons transfer at complex I has been reported to be associated with an increased production of superoxide radicals (Hensley et al., 2000). Rotenone induced a significant increase in the oxidation level of DHE, a widely used ROS-sensitive dye (Fig. 2A,B). The mean oxidation level of rotenone-treated HeLa cells was significantly lower when cultured without DC than when cultured with DC. The effect of rotenone on the subsequent activation of NF- $\kappa \mathrm{B}$, a redox-sensitive nuclear transcription factor, was further examined in the HeLa cells overexpressing human TFAM by the tetracycline-off system. The activation of NF- $\kappa \mathrm{B}$ in HeLa cells was assessed by visualizing its translocation from the cytoplasm to the nucleus after treatment with rotenone. Rotenone 
A
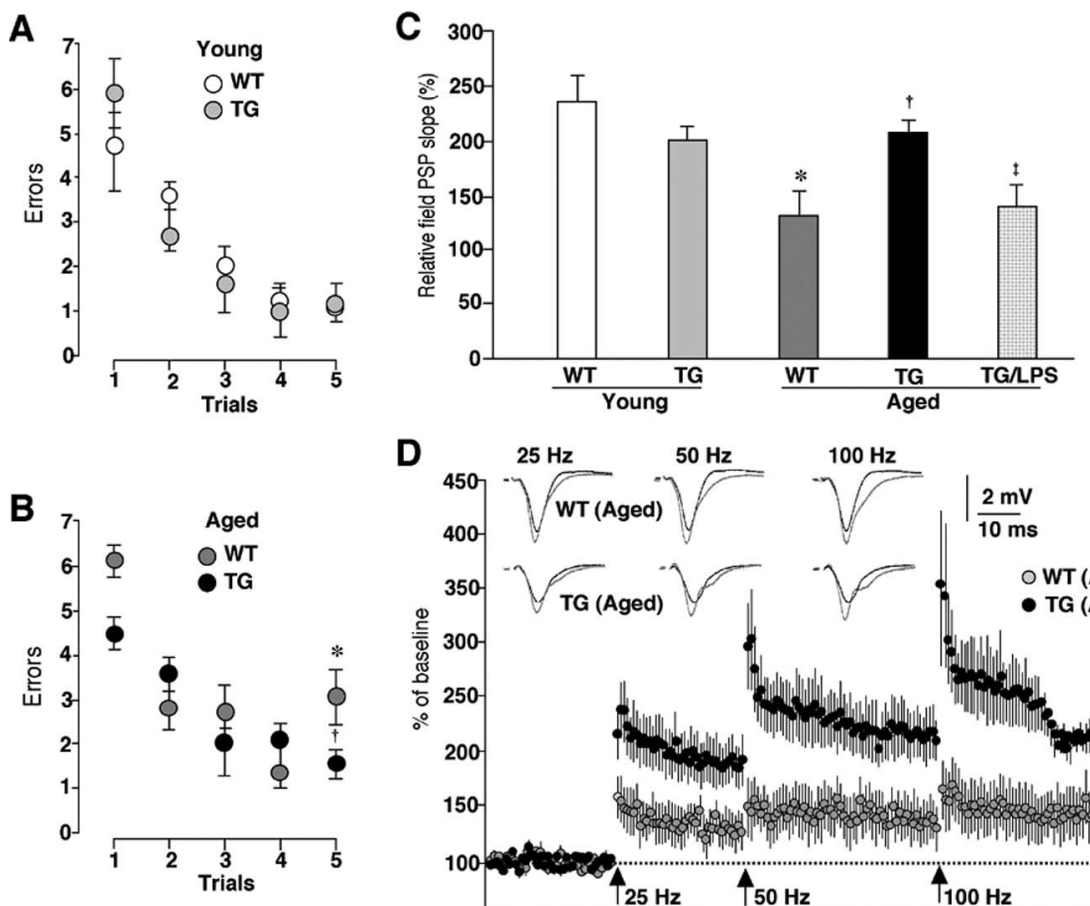

D

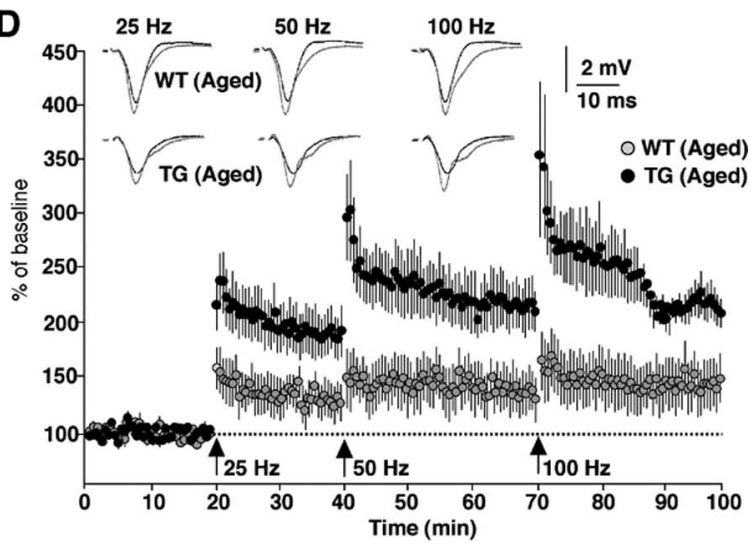

Figure 5. An amelioration of age-dependent decline of the working memory and the hippocampal LTP in the aged TG mice. $A$, $\boldsymbol{B}$, The mean number of errors during radial-arm water maze performance in the TG and WT mice of both the young $(\boldsymbol{A})$ and the aged groups $(\boldsymbol{B})$. Four consecutive acquisition trials (trials 1 - 4) followed by a 30 min retention trial (trial 5) were conducted. Each circle and bar represents the mean \pm SEM of six experiments. An asterisk indicates a significant difference versus the young WT mice $\left({ }^{*} p<0.05\right)$. A dagger indicates a significant difference versus the aged WT mice $\left({ }^{\dagger} p<0.05\right)$. $\boldsymbol{C}$, The mean relative EPSP slopes measured at $30 \mathrm{~min}$ after tetanic stimulation at $100 \mathrm{~Hz}$ in the Schaffer collateral-CA1 pathway of the WT and TG mice of both age groups and LPS-treated aged TG mice. Each column and bar represent the mean \pm SEM of six slices from three animals in the young WT group, three slices from three animals in the young TG group, three slices from three animals in the aged WT group, 11 slices from seven animals in the aged TG group, and 15 slices from five animals in the aged TG group subjected to intraperitoneally injection of LPS $(0.33 \mathrm{mg} / \mathrm{kg}) 4 \mathrm{~h}$ earlier. An asterisk indicates a significant difference versus the young WT mice $\left({ }^{*} p<0.05\right)$. A dagger indicates a significant difference versus the aged WT mice $\left({ }^{\dagger} p<0.05\right)$. A double dagger indicates a significant difference from the value of the aged TG mice $\left({ }^{\ddagger} p<0.05\right)$. D , The cumulative potentiation of EPSP slope after consecutive tetanic stimulation at 25, 50, and $100 \mathrm{~Hz}$ in the hippocampus of aged WT and TG mice. Each circle and bar represent the mean \pm SEM of three slices from three animals in the aged WT group, and 11 slices from seven animals in the aged TG group. The traces show the typical field EPSP before (black) and after stimulation at each frequency (gray).

also induced the NF- $\kappa \mathrm{B}$ nuclear translocation in HeLa cells cultured with DC. However, the mean ratio of translocated NF- $\kappa$ B in rotenone-treated HeLa cells was significantly lower when they were cultured without DC than when they were cultured with DC (Fig. $2 C ; D$, arrowheads). These results clearly indicate that the overexpression of TFAM prevents the overproduction of ROS originated from the mitochondria and inhibits the intracellular redox-sensitive signaling of NF- $\kappa \mathrm{B}$.

Amelioration of age-dependent increased oxidative stress and reduced activity of mitochondrial respiratory enzymes in the brain of aged TG mice

Next, the effect of TFAM overexpression on the ROS generation in the brain was examined using TG mice and their wild-type littermates. In the young TG mice, the human TFAM protein was expressed in the soluble extracts prepared from the whole brain, without any significant changes in the expression of the endogenous mouse Tfam protein (Fig. 3A). Immunostaining also showed human TFAM to be expressed in both neurons and glial cells in the brain parenchyma of the TG mice (Fig. 3B). Lipid peroxidation, which was indicated by TBARS, significantly increased in the brain tissue specimens of the aged WT mice. The increased lipid peroxi-

dation may therefore contribute to the senescent changes in the brain functions. However, the mean TBARS level in the brain tissues of the aged TG mice was significantly lower than that in the aged WT mice and comparable with that in the young group (Fig. 3C). Many studies have suggested a mechanistic link between mtDNA mutations, a loss of mitochondrial respiratory enzyme functions, and generation of ROS from the mitochondria. A decreased electron transfer activity has been observed in the mitochondria of experimental animals on aging (Navarro et al., 2005; Mao et al., 2006). The activity of complexes I and IV in the mitochondrial fractions prepared from the brain tissue specimens of the aged WT mice were significantly lower compared with the young WT mice, whereas those of complexes II and III were unaffected (Fig. 3D). These results are consistent with those of previous reports (Navarro et al., 2005; Mao et al., 2006). In the brain tissue specimens prepared from the TG mice, however, there was no age-dependent reduction in activity for any of the complexes (Fig. 3D). Therefore, the age-dependent decrease in enzymatic activities of complexes I and IV could be mainly a consequence of oxidative mtDNA damage. Furthermore, it is reasonable to consider that human TFAM effectively counteracted this oxidative mtDNA damage to rescue the age-dependent decrease in mitochondrial complex enzymatic activities.

\section{Amelioration of the aged-dependent impairment of motor learning and memory in aged TG mice}

The effects of TFAM overexpression were next observed regarding the agedependent impairment of the locomotor activity and the motor learning and memory using rotarod tests, because ROS are considered to be a major causal factor for the progressive age-dependent motor and learning functions.

The locomotor activities were measured by both the cylinder and line-crossing tests. The mean total number of both forepaw contacts and the incidence of line crossed significantly decreased with aging in both the WT and TG mice (Fig. 4A,B). The mean total number of forepaw contacts showed no significant difference between the aged WT mice and the aged TG mice (Fig. 4A). All groups of animals used in this study had an equal forelimb use. The mean total incidence of line crossed in the aged TG mice was larger than that in the aged WT mice, whereas the difference did not reach the statistical significance (Fig. $4 B$ ).

Next, the rotarod test was used to examine the effects of TFAM overexpression on the age-dependent impaired acquisition of skilled behavior. With the fixed speed rotarod protocol, both the young WT and TG mice could rapidly acquire the necessary skilled behavior on the rotating rod to prevent a fall. They were able to stay on the rod for the maximum time at both trained at speeds between 5 and $15 \mathrm{rpm}$ and tested at $15 \mathrm{rpm}$ (Fig. 4C). The aged WT mice showed an increase in the latency to fall across trials, but their score was much lower than that of the young 
group. During the test session, the average time spent on the rod significantly decreased with aging in the WT mice (Fig. $4 D)$. Furthermore, regardless of the progress during three trials at $15 \mathrm{rpm}$, the aged WT mice fell down from the rod in $\sim 60 \mathrm{~s}$ in the first trial in the test session on the next day (Fig. 4C,D). However, the aged TG mice could rapidly acquire the skilled behavior on the rotating rod similar to the young group at speeds with 5 and 10 rpm (Fig. 4C). In the task at a speed of 15 rpm, the aged TG mice showed a slow acquisition of the skilled behavior compared with the young group. Because of the fact that the mice had to turn their position against the direction of rotation and progress forward to maintain their equilibrium on the rod after the rod started to rotate, they needed to acquire the more skillful behavior at higher speeds. During the test session, however, the mean latency to fall of the aged TG mice significantly increased compared with that of the aged WT mice (Fig. 4D). Although the aged WT animals could not reach the maximum time during the test session for their low endurance, they stayed on the rod for more than their maximum time during the fixed speed protocol and at speed $>15 \mathrm{rpm}$ in the accelerating rotarod protocol (accelerate continuously from 4 to $40 \mathrm{rpm}$ over $300 \mathrm{~s}$ ) (data not shown). In addition, there was no difference in locomotive activation between WT and TG mice (Fig. 4A,B), thus suggesting that a decrease in the time spent on the rod was caused by an impairment of the acquisition of the skilled behavior rather than by a decline in their endurance or motivation. These results indicate that the age-dependent motor memory impairment markedly improved in the TG mice.

\section{Amelioration of the age-dependent decline of the working memory and the hippocampal LTP in the aged TG mice}

Next, the effects of TFAM overexpression on the age-dependent impairment of the working memory were examined using the radial arm water maze, which combines elements of a radial-arm maze and a water maze (Morgan et al., 2000). Both the WT and TG mice of the young group showed an average of four to six errors in the first trial and only one error in the retention trial (trial 5) (Fig. 5A). In both the WT and TG mice of the aged group, the animals showed four to six errors on the first trial. On the retention trial (trial 5), the mean number of errors in the aged TG mice was significantly lower than that in the aged group and it was comparable with that in the young group (Fig. 5B).

These observations prompted the additional examination of the effects of TFAM overexpression on the age-dependent decline in the hippocampal LTP, which is postulated to be a cellular substrate for hippocampus-dependent memory. The LTP experiments were performed on transverse hippocampal slices as described previously (Tomimatsu et al., 2002; Hayashi et al., 2006). The cumulative potentiation of the field EPSP slope was measured after consecutive tetanic stimulation at 25, 50, and $100 \mathrm{~Hz}$. When the relative field EPSP slope was measured at $30 \mathrm{~min}$ after between WT and TG slices.
B
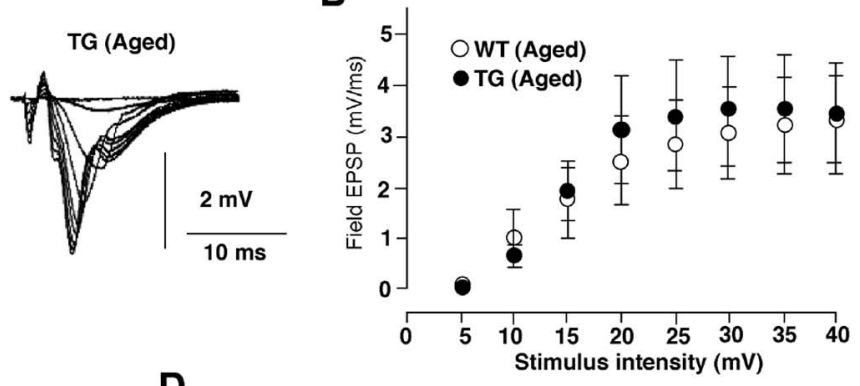

D

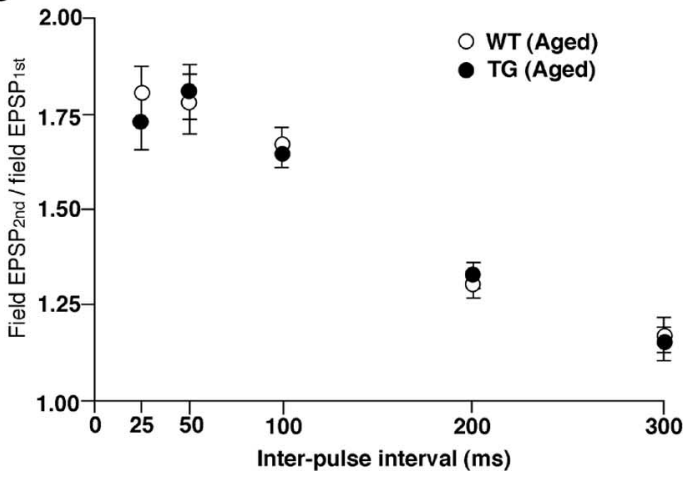

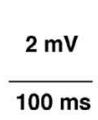

$100 \mathrm{~ms}$

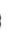

Figure 6. Effects of TFAM overexpression on basal synaptic transmission in the hippocampus. $A$, Superimposed traces of field EPSPs evoked by different stimulus intensities (5-40 V) from the CA1 subfield of hippocampal slices prepared from the aged WT mice. $\boldsymbol{B}$, The input- output relationship for the mean field EPSP slope plotted against stimulus intensity in the Schaffer

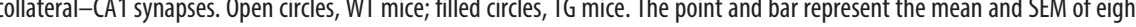
animals in the aged WT mice, and seven slices from seven animals in aged TG mice. No significant difference was observed

tetanic stimulation with $100 \mathrm{~Hz}$, there was no significant difference in the mean magnitude of LTP in the Schaffer collateralCA1 pathway between the young WT and TG mice (Fig. 5C). Consistent with previous studies (Okada et al., 1995), LTP in the Schaffer collateral-CA1 pathway was significantly lower in the aged WT mice than in the young WT mice (Fig. $5 C$ ). However, LTP was induced by conditioned stimuli even at a relatively low frequency ( 25 or $50 \mathrm{~Hz}$ ) in the aged TG mice (Fig. $5 D$ ). The mean relative field EPSP slope measured at 30 min after tetanic stimulation with $100 \mathrm{~Hz}$ in the aged TG mice was significantly greater than that in the aged WT mice and it was also comparable with that in the young group (Fig. 5C,D).

However, there was no significant difference in either the basal synaptic transmission (Fig. 6A,B) or the paired-pulse facilitation (Fig. 6C,D) between the aged WT and TG mice. These results clearly indicate that an overexpression of TFAM significantly ameliorates the age-dependent deficits in the working memory and the hippocampal LTP.

\section{Amelioration of increased oxidation and inflammation in the brain of the aged TG mice}

ROS have been associated with normal aging and age-dependent neurodegenerative disorders (Watson et al., 2006). The localization of oxidative damages was examined in the hippocampus and other brain regions. The immunoreactivity for HNE and 8-oxo$\mathrm{dG}$, which are formed by oxidant interactions with lipids and DNA, respectively, increased in the aged WT mouse brains. In- 


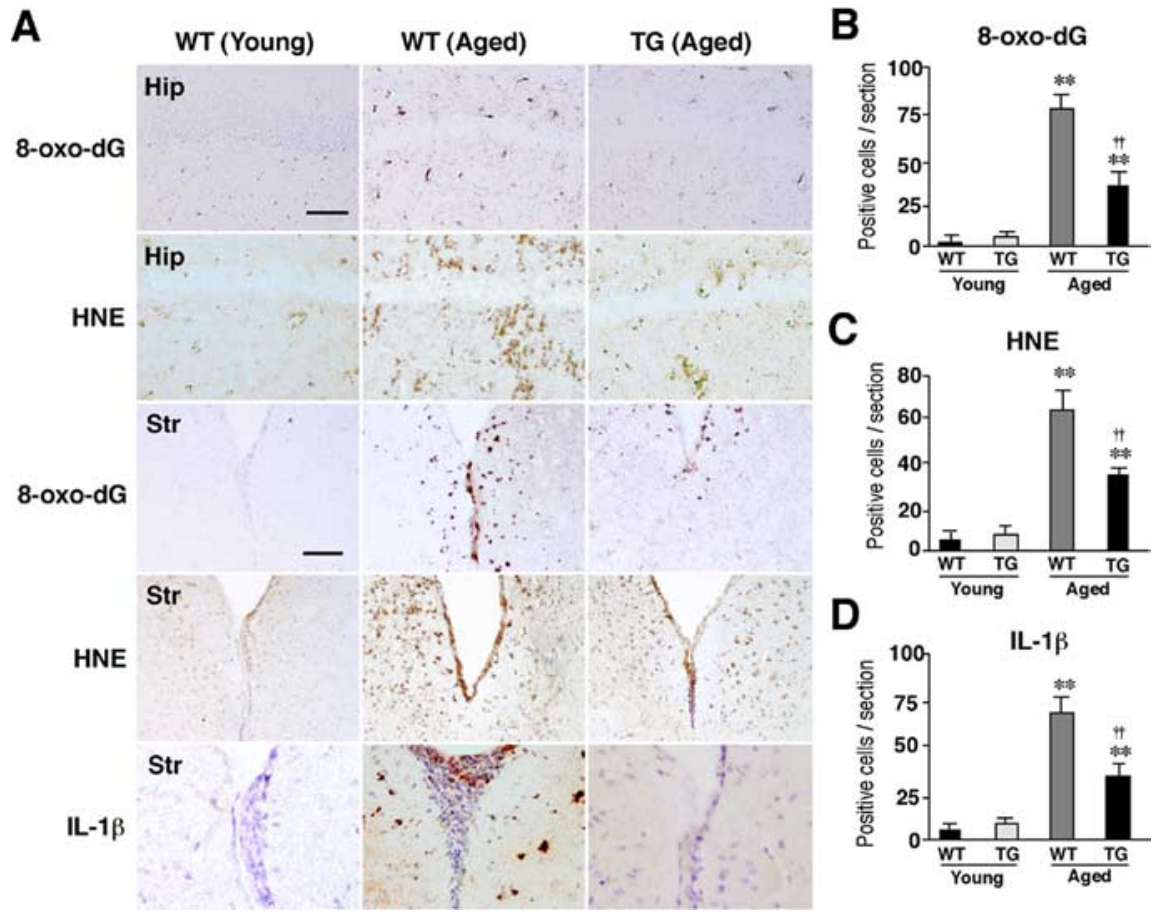

Figure 7. Amelioration of ROS-mediated oxidation of cell components and inflammation in the hippocampus of the aged TG mice. $\boldsymbol{A}$, Immunohistochemical staining for 8-0x0-dG and HNE in the CA1 hippocampal subfield (Hip) and the periventricular area of the striatum (Str) of the young WT, the aged WT, and the aged TG mice. Scale bars, $50 \mu \mathrm{m}$. $\boldsymbol{B}-\boldsymbol{D}$, The mean number of positive cells for 8-0x0-dG (B), HNE (C), and IL-1 $\beta$ /cells $(\boldsymbol{D})$ in the hippocampal CA1 subfield of the WT, the TG, and the LPS-treated TG mice of the aged group. Each column and bar represent the mean \pm SEM of nine sections from three animals. The asterisks indicate significant differences versus the young group $\left({ }^{* *} p<0.01\right)$. The daggers indicate significant differences versus the aged WT mice $\left({ }^{\dagger+} p<0.01\right)$.

creased immunoreactivity was prominent especially in the hippocampus and the periventricular areas of the striatum (Fig. 7A$C)$. In contrast, the immunoreactivity of these markers for oxidative stress was barely detectable in the brain parenchyma of the aged TG mice (Fig. $7 A-C$ ). The immunoreactivity for IL- $1 \beta$ also significantly increased in the periventricular areas (Fig. $7 A, D$ ) and the hippocampus (data not shown) of the aged WT mice but not those brain regions of the aged TG mice. Double immunofluorescence staining was performed to elucidate the cellular sources for 8-oxo-dG, HNE, and IL-1 $\beta$. Rather surprisingly, the immunoreactivity for both 8-oxo-dG and HNE corresponded closely with microglia exhibiting activated morphology and partially with neurons, but not with astrocytes localized in the periventricular area of the aged WT mice (Fig. $8 A, B$ ). The relatively intense immunoreactivity for IL- $1 \beta$ corresponded well with that for both Ibal and GFAP, but not MAP2 in the periventricular areas (Fig. 8C) and the hippocampus (Fig. 9C) of the aged WT mice. In the hippocampus of the aged WT mice, the immunoreactivity for either 8-oxo-dG (Fig. $8 D$, red) or HNE (data not shown) was found mainly in glial cells and only partially in neurons that were intensely stained with YOYO-1 (green). The immunoreactivity for 8-oxo-dG (Fig. $8 \mathrm{~F}$ ) and HNE (Fig. 8G) found in the stratum radiatum corresponded well with microglia. However, the immunoreactivity for either 8-oxo-dG (Fig. 8 E) or HNE (data not shown) was barely detectable in the hippocampus of the aged TG mice.

Recent accumulating evidence indicates that intracellular ROS is capable of activating redox-dependent signal transduction cascades and transcription factors including NF- $\kappa \mathrm{B}$ and mitogen-activated protein (MAP) kinases in various cell types

\section{Discussion}

including microglia (Pawate et al., 2004; Yamasaki et al., 2007). The activation of $\mathrm{NF}-\kappa \mathrm{B}$ and MAP kinases is closely associated with the expression of inflammatory mediators including IL- $1 \beta$ in microglia. Furthermore, inflammatory mediators including IL-1 $\beta$ secreted from microglia have been recently reported to play a pivotal role in the attenuation of the working memory (Gemma et al., 2005) and the hippocampal LTP in aged rats (Griffin et al., 2006). Therefore, the relationship between the oxidative damage of mtDNA, the expression level of IL- $1 \beta$, and the magnitude of the hippocampal LTP was examined by treatment with LPS, which is known to increase the generation of mitochondrial ROS (Woo et al., 2004; Emre et al., 2007). At $4 \mathrm{~h}$ after the systemic injection of LPS, the mean level of IL- $1 \beta$ in the whole brain of the aged TG mice significantly increased, thus reaching a similar level to that of the aged WT mice (Fig. 9A,B). However, the mean level of IL- $1 \beta$ in the whole brain of the LPS-treated aged TG mice was significantly lower that of the LPS-treated aged WT mice (Fig. 9A,B). However, the immunoreactivity for 8-oxo-dG corresponded closely with that for Cyt $b$, a marker for the mitochondria, was observed in the hippocampus of the aged WT mice. In contrast, there was slight immunoreactivity for either IL- $1 \beta$ or 8-oxo-dG in the hippocampus of the aged TG mice. On treatment with LPS, the immunoreactivity for both IL- $1 \beta$ and 8-oxo-dG markedly increased in the hippocampus of the aged TG mice (Fig. 9C). The immunoreactive products for IL-1 $\beta$ showed a specked appearance, thus suggesting the localization of IL- $1 \beta$ in lysosomes where IL- $1 \beta$ colocalizes with lysosomal enzymes (Gardella et al., 2001; Qu et al., 2007). The mean immunofluorescence intensity of IL- $1 \beta$ /cell in the hippocampus of the LPS-treated aged TG mice was significantly higher than that in the aged TG mice and it was also comparable with that in the aged WT mice (Fig. 9C,D). At the same time, the mean immunofluorescence intensity of 8-oxo-dG/mitochondria in the hippocampus of the LPS-treated aged TG mice was also significantly higher than that in the aged TG mice (Fig. 9C,E). Finally, LTP in the Schaffer collateral-CA1 pathway was measured in hippocampal slices prepared from the LPS-treated aged TG mice. As shown in Figure 5C, the mean magnitude of LTP in the LPS-treated aged TG mice was significantly lower than that of none-treated aged TG mice (143.86 $\pm 10.17 \% ; p<0.05)$.

These observations strongly suggest that overexpressed human TFAM also significantly suppressed mitochondrial ROS generation and the subsequent IL- $1 \beta$ production by microglia in the brain. Furthermore, the magnitude of the hippocampal LTP was inversely correlated with the expression level of IL- $1 \beta$ and the severity of mtDNA damage in microglia.

The mitochondrial theory of aging states that the original damage to mtDNA is induced by the continuous production of ROS (Beckman and Ames, 1998; Harman, 2006). The most important 

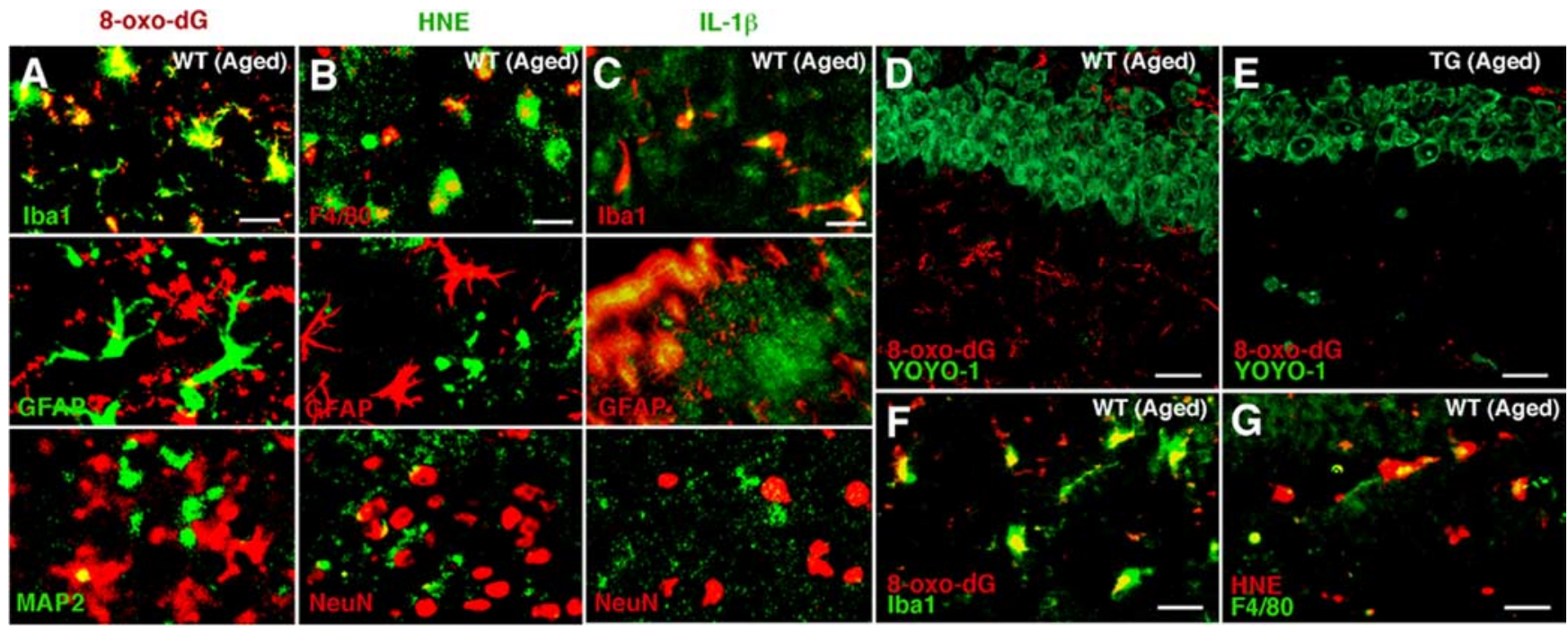

Figure 8. Immunofluorescent CLSM images for 8-oxo-dG, HNE, and IL-1 $\beta$ in the striatum and the hippocampus. $A-C$, Immunofluorescence for 8-0xo-dG $(\boldsymbol{A})$, HNE $(\boldsymbol{B})$, and IL-1 $\beta(\boldsymbol{C})$ with cell type markers (Iba1, F4/80 for microglia, GFAP for astrocytes, MAP2 and NeuN for neurons) in the periventricular area of the striatum of the aged WT mice. Scale bars: $A-C, 30 \mu \mathrm{m}$. $\boldsymbol{D}, E$, Immunofluorescence for 8-oxo-dG (red) with YoY0-1-stained neurons (green) in the hippocampal CA1 subfield of the aged WT (D) and TG (E) mice. Scale bars: $\boldsymbol{D}, \boldsymbol{E}, 20 \mu \mathrm{m} . \boldsymbol{F}, \boldsymbol{G}$, Immunofluorescence for 8-0xo-dG $(\boldsymbol{F})$ and HNE $(\boldsymbol{G})$ with markers of microglia (Iba1 and F4/80) in the hippocampal CA1 subfield of the aged WT mice. Scale bars: $\boldsymbol{F}, \boldsymbol{G}, 5 \mu \mathrm{m}$.

finding in the current study is that the overexpression of human TFAM reduced age-dependent oxidative damages of mtDNA mainly in microglia, thus preventing the age-dependent impairments in the motor and working memories in mice. These beneficial effects of human TFAM overexpression were attributable to functional improvements in the brain but not in the musculature in the aged TG mice. Considering (1) the abundance of TFAM, (2) the structure of TFAM as high-mobility group DNA-binding protein, and (3) the association of TFAM with MtDNA protein complexes (Alam et al., 2003; Kanki et al., 2004a; Kang and Hamasaki, 2005), (4) human TFAM dose not appear to work as a transcription factor in a mouse cell (Ohgaki et al., 2007), human TFAM can cover the whole region of a mtDNA forming nucleoid to protect it from oxidative modifications or additional damage without modulation of gene expression (Kanki et al., 2004a; Kang and Hamasaki, 2005). The present study clearly demonstrated a causal relationship among mitochondrial ROS, mitochondrial dysfunction, and deficits in the brain functions during the process of aging.

The results of this study revealed that microglia are the main cellular source of oxidation products including HNE and 8-oxo-dG in the brain of the WT mice. It was also noted that the accumulation of oxidation products in microglia was more marked in specific brain areas including the hippocampus and the periventricular area of the striatum. These marked oxidative stresses on microglia in the hippocampus and striatum are considered to be closely associated with the age-dependent memory deficits, because these brain regions play key roles in the formation of motor and working memories, respectively (Morris et al., 1982; Albin et al., 1989). These observations remain, however, somewhat puzzling because the most severe age-dependent mtDNA injury and greatest ROS production in the brain are believed to occur in neurons that are long-living postmitotic cells. Liu et al. (2002) demonstrated RNA to be the predominant oxidized neuronal nucleic acid in the aged rat brain. Therefore, RNA being the predominant oxidized neuronal nucleic acid in the aged animal brain may explain the paucity of oxidative mtDNA damage in neurons of the aged WT mice in the present immunohistochemical analysis using anti-8-oxo-dG antibody. However, some evidence suggests that the mitochondrial turnover in microglia is extremely slow and that abundant damaged mitochondria, which can generate excessive ROS, may accumulate in microglia. A recent study showed the subunit c of the mitochondrial ATP synthase complex to accumulate most intensively in microglia in the brain of the mice deficient for cathepsin D, which is a protease responsible for proteolytic degradation of subunit c (Yamasaki et al., 2007). Furthermore, Lawson et al. (1992) revealed a slow microglial turnover in the normal adult mouse brain, although microglia are replaceable cells. The age-dependent changes in the mitochondrial functions and ROS production in microglia are thus expected to be elucidated in future studies.

The current observations showed that TFAM overexpression suppressed the ROS generation induced by rotenone and the subsequent activation of NF- $\kappa \mathrm{B}$ in HeLa cells. ROS induced by rotenone were generated from the mitochondria because an impaired electron transfer at complex I is associated with an increased production of ROS in the mitochondria (Schönfeld and Reiser, 2006). Furthermore, a decrease in the enzymatic activity of complex I in the range of $16-30 \%$ is sufficient to stimulate mitochondrial ROS generation (Sipos et al., 2003). Therefore, a decrease in the activity of both complexes I and IV by approximately one-third in the brain of the aged WT mice could induce excessive mitochondrial ROS generation. These excess ROS may further cause oxidative DNA damage, lipid peroxidation, and IL- $1 \beta$ production through activation of NF- $\kappa$ B. Therefore, human TFAM overexpression may also reduce excessive mitochondrial ROS generation in the brain during aging and the subsequent oxidative damage and inflammatory responses through the protection of mtDNA against oxidative injury.

Although the observations noted herein showed that the systemic injection of LPS could further activate microglia to produce IL- $1 \beta$ in the brain of the aged TG mice, the mean amount of IL- $1 \beta$ in the brain of the LPS-treated aged TG mice was significantly lower than that of the LPS-treated aged WT mice. LPS is therefore suggested to activate microglia by a multitude of receptors and interacting pathways (Qin et al., 2005), with the production of ROS. Recently, mitochondria have been found to contribute to LPS-induced ROS signaling in macrophages (Woo et al., 

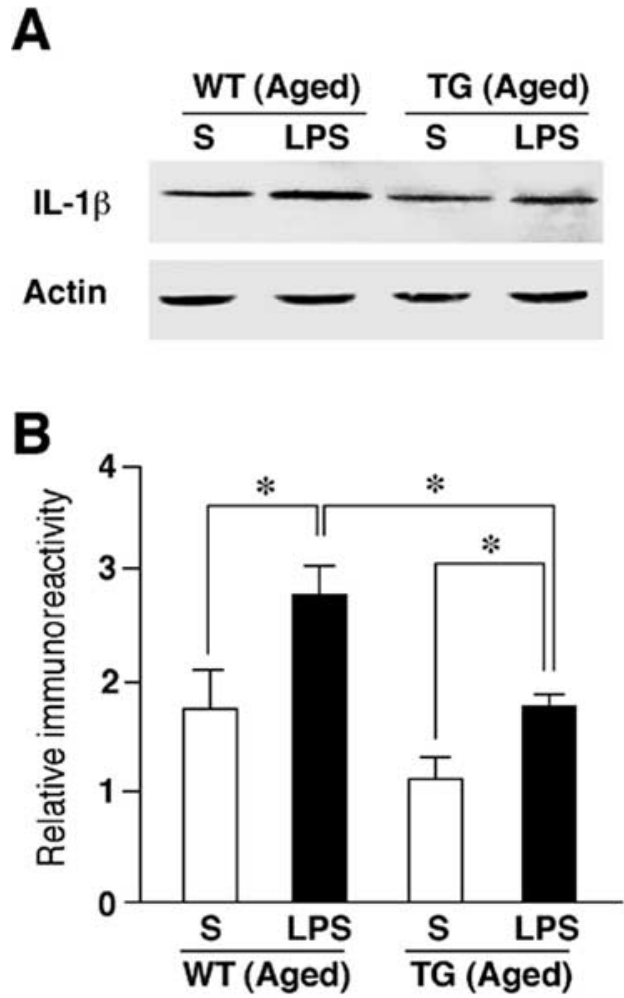
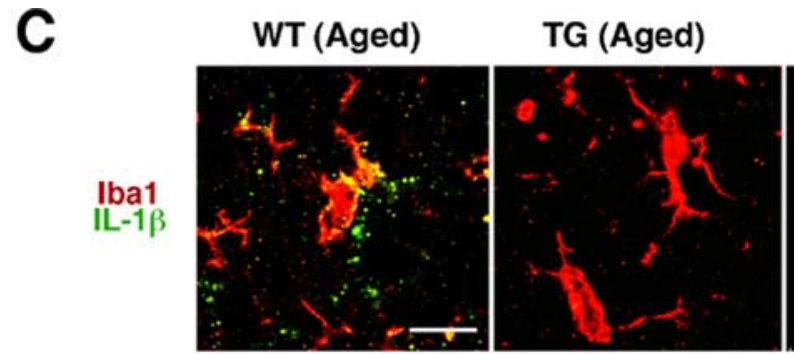

TG (Aged)/LPS
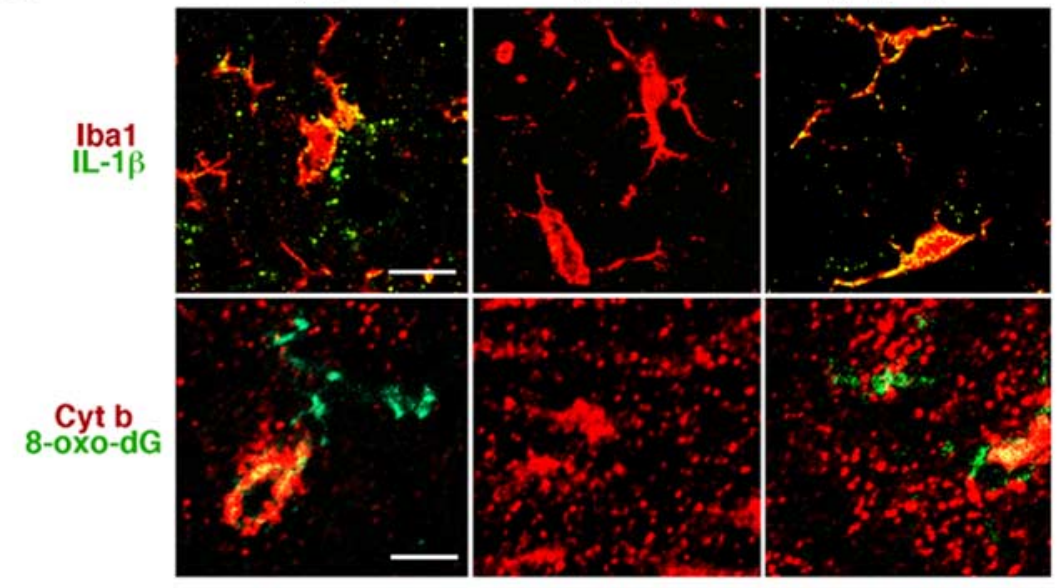

D.
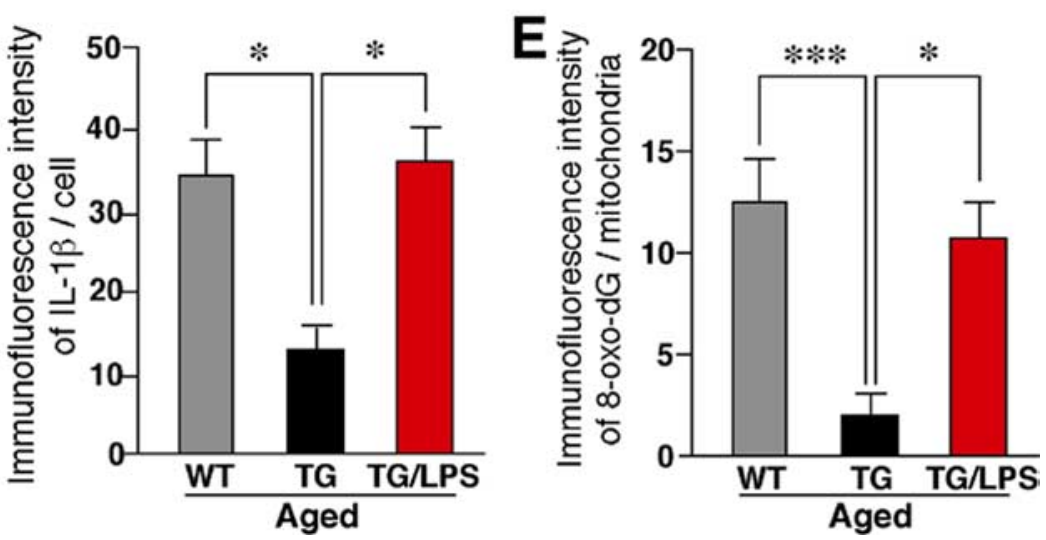

Figure 9. Increased expression of IL-1 $\beta$ in the hippocampus after the systemic injection of LPS and the inhibitory effect of the TFAM overexpression. $A$, Immunoblot analysis of IL- $1 \beta$ in the whole brain of the aged WT and TG mice subjected to intraperitoneal injection of saline (S) or LPS $(0.33 \mathrm{mg} / \mathrm{kg}) 4 \mathrm{~h}$ earlier. $\boldsymbol{B}$, The mean protein level of IL- $1 \beta$. The mean relative immunoreactivity was determined using the level of actin as an internal control. Each column and bar represent the mean and SEM of three experiments, respectively. The asterisks indicate significant differences between the values $\left({ }^{*} p<0.05\right.$ ). C, Immunofluorescent CLSM images for IL-1 $\beta$ (green) with the microglial marker lba1 (red; top row), and 8-oxo-dG (green) with the mitochondrial marker Cyt $b$ (red; bottom row) in the hippocampal CA1 subfield of the aged WT, the aged TG, and the LPS-treated aged TG mice. Scale bars: top row, $10 \mu \mathrm{m}$; bottom row, $5 \mu \mathrm{m}$. $D$, The mean immunofluorescence intensity of IL-1 $\beta$ /cell in the hippocampal CA1 subfield of the WT, the TG, and the LPS-treated TG mice of the aged group. Each column and bar represent the mean \pm SEM of nine sections from three animals. The asterisks indicate significant differences between the values $\left({ }^{*} p<0.05\right)$. $E$, The mean immunofluorescence intensity of $8-0 \times 0$-dG/mitochondria in the hippocampal CA1 subfield of the WT, the TG, and the LPS-treated TG mice of the aged group. Each column and bar represent the mean \pm SEM of seven sections from two animals. The asterisks indicate significant differences between the values $\left({ }^{* * *} p<0.0001 ;{ }^{*} p<0.05\right)$.

2004; Emre et al., 2007). It is therefore conceivable that the overexpression of TFAM also inhibited the LPS-induced mitochondrial ROS generation to reduce oxidative mtDNA damage and the IL- $1 \beta$ levels in the brain. There is increasing evidence that neuroinflammation mediated by activated microglia plays a major causative role in age-dependent deficit of the working memory (Gemma et al., 2005) and the hippocampal LTP (Griffin et al., 2006). It is therefore reasonable to consider that TFAM overexpression may inhibit any excessive ROS generation caused by a reduced mitochondrial respiratory chain enzymatic activity in microglia during aging, because ROS can activate NF- $\kappa \mathrm{B}$, which integrates oxidative stress and the inflammatory pathways $(\mathrm{Pa}-$ wate et al., 2004). Additional clarification of the mechanisms by which TFAM exhibits an antioxidant effect and maintains the mitochondrial function may eventually lead to the development of an antiaging strategy to preserve the brain functions.

\section{References}

Alam TI, Kanki T, Muta T, Ukaji K, Abe Y, Nakayama H, Takio K, Hamasaki N, Kang D (2003) Human mitochondrial DNA is packaged with TFAM. Nucleic Acids Res 31:1640-1645.
Albin RL, Young AB, Penney JB (1989) The functional anatomy of basal ganglia disorders. Trends Neurosci 12:366-375.

Beckman KB, Ames BN (1998) The free radical theory of aging matures. Physiol Rev 78:547-581.

Corral-Debrinski M, Horton T, Lott MT, Shoffner JM, Beal MF, Wallace DC (1992) Mitochondrial DNA deletions in human brain: regional variability and increase with advanced age. Nat Genet 2:324-329.

Emre Y, Hurtaud C, Nübel T, Criscuolo F, Ricquier D, Cassard-Doulcier AM (2007) Mitochondria contribute to LPS-induced MAPK activation via uncoupling protein UCP2 in macrophages. Biochem J 402:271-278.

Forster MJ, Dubey A, Dawson KM, Stutts WA, Lal H, Sohal RS (1996) Agerelated losses of cognitive function and motor skills in mice are associated with oxidative protein damage in the brain. Proc Natl Acad Sci U S A 93:4765-4769.

Gardella S, Andrei C, Lotti LV, Poggi A, Torrisi MR, Zocchi MR, Rubartelli A (2001) $\mathrm{CD}^{+} \mathrm{T}$ lymphocytes induce polarized exocytosis of secretory lysosomes by dendritic cells with release of interleukin- $1 \beta$ and cathepsin D. Blood 98:2152-2159.

Gemma C, Fister M, Hudson C, Bickford PC (2005) Improvement of memory for context by inhibition of caspase-1 in aged rats. Eur J Neurosci 22:1751-1756.

Griffin R, Nally R, Nolan Y, McCartney Y, Linden J, Lynch MA (2006) The 
age-related attenuation in long-term potentiation is associated with microglial activation. J Neurochem 99:1263-1272.

Harman D (2006) Free radical theory of aging: an update: increasing the functional life span. Ann N Y Acad Sci 1067:10-21.

Hayashi Y, Tomimatsu Y, Suzuki H, Yamada J, Wu Z, Yao H, Kagamiishi Y, Tateishi N, Sawada M, Nakanishi H (2006) The intra-arterial injection of microglia protects hippocampal CA1 neurons against global ischemiainduced functional deficits in rats. Neuroscience 142:87-96.

Hensley K, Kotake Y, Sang H, Pye QN, Wallis GL, Kolker LM, Tabatabaie T, Stewart CA, Konishi Y, Nakae D, Floyd RA (2000) Dietary choline restriction causes complex I dysfunction and increased $\mathrm{H}_{2} \mathrm{O}_{2}$ generation in liver mitochondria. Carcinogenesis 21:983-989.

Iancu R, Mohapel P, Brundin P, Paul G (2005) Behavioral characterization of a unilateral 6-OHDA-lesion model of Parkinson's disease in mice. Behav Brain Res 162:1-10.

Ide T, Tsutsui H, Kinugawa S, Utsumi H, Kang D, Hattori N, Uchida K, Arimura K, Egashira K, Takeshita A (1999) Mitochondrial electron transport complex I is a potential source of oxygen free radicals in the failing myocardium. Circ Res 85:357-363.

Ikeuchi M, Matsusaka H, Kang D, Matsushima S, Ide T, Kubota T, Fujiwara T, Hamasaki N, Takeshita A, Sunagawa K, Tsutsui H (2005) Overexpression of mitochondrial transcription factor A ameliorates mitochondrial deficiencies and cardiac failure after myocardial infarction. Circulation 112:683-690.

Kajitani K, Yamaguchi H, Dan Y, Furuichi M, Kang D, Nakabeppu Y (2006) MTH1, an oxidized purine nucleoside triphosphatase, suppresses the accumulation of oxidative damage of nucleic acids in the hippocampal microglia during kainate-induced excitotoxicity. J Neurosci 26:1688-1698.

Kang D, Hamasaki N (2005) Mitochondrial transcription factor A in the maintenance of mitochondrial DNA: overview of its multiple roles. Ann N Y Acad Sci 1042:101-108.

Kanki T, Nakayama H, Sasaki N, Takio K, Alam TI, Hamasaki N, Kang D (2004a) Mitochondrial nucleoid and transcription factor A. Ann N Y Acad Sci 1011:61-68.

Kanki T, Ohgaki K, Gaspari M, Gustafsson CM, Fukuoh A, Sasaki N, Hamasaki N, Kang D (2004b) Architectural role of mitochondrial transcription factor A in maintenance of human mitochondrial DNA. Mol Cell Biol 24:9823-9834.

Lawson LJ, Perry VH, Gordon S (1992) Turnover of resident microglia in the normal adult mouse brain. Neuroscience 48:405-415.

Lin MT, Simon DK, Ahn CH, Kim LM, Beal MF (2002) High aggregate burden of somatic mtDNA point mutations in aging and Alzheimer's disease brain. Hum Mol Genet 11:133-145.

Liu J, Head E, Gharib AM, Yuan W, Ingersoll RT, Hagen TM, Cotman CW, Ames BN (2002) Memory loss in old rats is associated with brain mitochondrial decay and RNA/DNA oxidation: partial reversal by feeding acetyl-L-carnitine and/ or R- $\alpha$-lipoic acid. Proc Natl Acad Sci U S A 99:2356-2361.

Mao L, Zabel C, Wacker MA, Nebrich G, Sagi D, Schrade P, Bachmann S, Kowald A, Klose J (2006) Estimation of the mtDNA mutation rate in aging mice by proteome analysis and mathematical modeling. Exp Gerontol 41:11-24.

Morgan D, Diamond DM, Gottschall PE, Ugen KE, Dickey C, Hardy J, Duff K, Jantzen P, DiCarlo G, Wilcock D, Connor K, Hatcher J, Hope C, Gordon M, Arendash GW (2000) A $\beta$ peptide vaccination prevents memory loss in an animal model of Alzheimer's disease. Nature 408:982-985.
Morris RG, Garrud P, Rawlins JN, O’Keefe J (1982) Place navigation impaired in rats with hippocampus lesions. Nature 297:681-683.

Navarro A, Sánchez Del Pino MJ, Gómez C, Peralta JL, Boveris A (2002) Behavioral dysfunction, brain oxidative stress, and impaired mitochondrial electron transfer in aging mice. Am J Physiol Regul Integr Comp Physiol 282:R985-R992.

Navarro A, Gomez C, López-Cepero JM, Boveris A (2004) Beneficial effects of moderate exercise on mice aging: survival, behavior, oxidative stress, and mitochondrial electron transfer. Am J Physiol Regul Integr Comp Physiol 286:R505-R511.

Navarro A, Gómez C, Sánchez-Pino MJ, González H, Bández MJ, Boveris AD, Boveris A (2005) Vitamin E at high doses improves survival, neurological performance, and brain mitochondrial function in aging male mice. Am J Physiol Regul Integr Comp Physiol 289:R1329-R1399.

Ohgaki K, Kanki T, Fukuoh A, Kurisaki H, Aoki Y, Ikeuchi M, Kim SH, Hamasaki N, Kang D (2007) The C-terminal tail of mitochondrial transcription factor A markedly strengthens its general binding to DNA. J Biochem 141:201-211.

Okada M, Nakanishi H, Tamura A, Urae A, Mine K, Yamamoto K, Fujiwara M (1995) Long-term spatial cognitive impairment after middle cerebral artery occlusion in rats: no involvement of the hippocampus. J Cereb Blood Flow Metab 15:1012-1021.

Parisi MA, Clayton DA (1991) Similarity of human mitochondrial transcription factor 1 to high mobility group proteins. Science 252:965-969.

Pawate S, Shen Q, Fan F, Bhat NR (2004) Redox regulation of glial inflammatory response to lipopolysaccharide and interferon $\gamma$. J Neurosci Res 77:540-551.

Qin L, Li G, Qian X, Liu Y, Wu X, Liu B, Hong JS, Block ML (2005) Interactive role of the Toll-like receptor 4 and reactive oxygen species in LPSinduced microglia activation. Glia 52:78-84.

Qu Y, Franchi L, Nunez G, Dubyak GR (2007) Nonclassical IL-1 $\beta$ secretion stimulated $\mathrm{P} 2 \mathrm{X} 7$ receptors is dependent on inflammasome activation and correlated with exosome release in murine macrophages. J Immunol 179:1913-1925.

Schönfeld P, Reiser G (2006) Rotenone-like action of the branched-chain phytanic acid induces oxidative stress in mitochondria. J Biol Chem 281:7136-7142.

Sipos I, Tretter L, Adam-Vizi V (2003) Quantitative relationship between inhibition of respiratory complexes and formation of reactive oxygen species in isolated nerve terminals. J Neurochem 84:112-118.

Tillerson JL, Cohen AD, Caudle WM, Zigmond MJ, Schallert T, Miller GW (2002) Forced nonuse in unilateral parkinsonian rats exacerbates injury. J Neurosci 22:6790-6799.

Tomimatsu Y, Idemoto S, Moriguchi S, Watanabe S, Nakanishi H (2002) Proteases involved in long-term potentiation. Life Sci 72:355-361.

Watson JB, Arnold MM, Ho YS, O’Dell TJ (2006) Age-dependent modulation of hippocampal long-term potentiation by antioxidant enzymes. J Neurosci Res 84:1564-1574.

Woo CH, Lim JH, Kim JH (2004) Lipopolysaccharide induces matrix metalloproteinase- 9 expression via a mitochondrial reactive oxygen species-p38 kinase-activator protein-1 pathway in raw 264.7 cells. J Immunol 173:6973-6980.

Yamasaki R, Zhang J, Koshiishi I, Sastradipura Suniarti DF, Wu Z, Peters C, Schwake M, Uchiyama Y, Kira J, Saftig P, Utsumi H, Nakanishi H (2007) Involvement of lysosomal storage-induced p38 MAP kinase activation in the overproduction of nitric oxide by microglia in cathepsin D-deficient mice. Mol Cell Neurosci 35:573-584. 